\title{
СОЗДАНИЕ НОВЫХ СОРТОВ СЛИВЫ КИТАЙСКОЙ НА УРАЛЕ
}

\author{
T. N. Slepneva, M. N. Matyunin
}

\section{THE CREATION OF NEW CHINESE PLUM VARIETIES IN THE URALS}

Слепнева Татьяна Николаевна - асп., мл. науч. сотр. Уральского федерального аграрного научно-исследовательского центра УрО РАН, г. Екатеринбург. E-mail: tatyana_slepneva@mail.ru Матюнин Михаил Николаевич - канд. с.-х. наук, науч. сотр. Федерального Алтайского научного центра агробиотехнологий, Республика Алтай, г. Горно-Алтайск. E-mail: tatyana_slepneva@mail.ru

Цель исследования - создать новый сорт сливы китайской, устойчивый к абио- и биотическим фракторам региона, урожайный, с высококачественными крупноплодными плодами для пополнения существующего районированного сортимента Урала. Объекты исследования: 1) деревья сорта Сапфир - в селекционном саду 1995 г. посадки (ФГУП «Горно-Алтайское», Республика Алтай, с. Чемал); 2) вегетативно размноженные растения, на участке конкурсного изучения 2009 г. посадки на Челябинском государственном плодово-ягодном сортоиспытательном участке (Челябинская область, Красноармейский район). Конкурсное испьтание заложено по методике Государственного сортоиспытания. В качестве контроля - районированный по Уральскому региону сорт - Уральская золотистая селекции Южно-Уральского научно-исследовательского института садоводства и картофрелеводства - фрилиала ФГБНУ «Уральский федеральный аграрный научно-исследовательский центр Уральского отделения Российской академии наук» (е. Челябинск). Изучаемые сорта привиты на сеянцы вишни песчаной (Prunus pumila L.). Схема посадки $5 \times 3$ м. Участок на богаре. Система содержания междурядий в саду - черньй пар. Агротехника общепринятая для воздельвания сливы на Южном Урале. Все исследования выполнены согласно общепринятым методикам. Дана морфологическая, биологическая и хозяйственная характеристика нового сорта сливы
Slepneva Tatyana Nikolaevna - Post-Graduate Student, Junior Staff Scientist, Ural Federal Agrarian Research Center RAS UrB, Yekaterinburg.

E-mail: tatyana_slepneva@mail.ru

Matyunin Mikhail Nikolaevich - Cand. Agr. Sci., Staff Scientist, Federal Altai Research Center of Agrobiotechnologies, Altai Republic, Gorno-Altaisk. E-mail: tatyana_slepneva@mail.ru

китайской Сапфир алтайской селекции. Сорт выделен за высокие адаптивные свойства к абио- и биотическим факторам, высокие вкусовые качества плодов, стабильную урожайность, крупноплодность. Средняя масса плодов составляет 25,5 2, округлой формы. Покровная окраска синяя с сильным восковым налетом. Средняя урожайность 5,3 m/2а. Сорт устойчив к грибным заболеваниям. Сорт сливы Сапфир позволит качественно пополнить районированный сортимент сливы Уральского региона.

Ключевые слова: Prunus salicina, зимостойкость, селекция, урожайность, качество плодов, северное садоводство, Уральский ре¿Uон.

The research objective was to create a new variety of Chinese plum steady to abio-and to biotic factors of the region, fruitful, with high-quality largefruited fruits for the replenishment of existing zoned assortment of the Urals. The objects of the research were: 1) trees of Sapphire variety - in the selection garden of 1995 of planting (Federal State Unitary Enterprise 'Gorno-Altayskoye', Altai Republic, the village of Chemal); 2) vegetatively propagated plants, on the site of competitive studying of 2009 of planting on the Chelyabinsk state fruit and berry variety testing site (Chelyabinsk Region, Krasnoarmeisk district). Competitive test was made by the technique of the State variety testing. As the control the variety zoned in the Ural Region - Ural golden selections of the Southern Ural Research 
Institute of Gardening and Potato Growing - FSBRI Branch "Ural Federal Agrarian Research Center of the Ural Branch of the Russian Academy of Sciences" (Chelyabinsk). The studied varieties were imparted on seedlings of sandy cherry (Prunus pumila L.). The scheme of planting was $5 \times 3 \mathrm{~m}$. The site was on bogara. The system of row-spacings in the garden was black fallow. The agrotechnology was standard for plum cultivation in the South Urals. All the researches were made according to the standard techniques. Morphological, biological and economic characteristic of a new Chinese Sapphire plum variety of Altai selection was given. The variety was distinguished for high adaptive properties to abio-and to biotic factors, high palatability of fruits, stable yield and large fruits. The average weight of the fruit of roundish form was $25.5 \mathrm{~g}$. The integument was blue with a strong waxy coating. Average productivity was 5.3 thectare. The variety was steady to fungal diseases. The plum variety Sapphire will allow filling up zoned assortment of plum of the Ural Region qualitatively.

Keywords: Prunus salicina, winter hardiness, selection, productivity, fruit quality, northern horticulture, Ural region.

Введение. В настоящее время в суровых условиях России ведется селекция как плодовых, так и ягодных культур, в результате которой созданы новые высокопродуктивные сорта $[7,8$, $11,12]$.

Сортимент косточковых культур на Урале и в Сибири пополняется и обновляется за счет сортов, созданных селекционерами в местных условиях. В настоящее время в Уральском регионе районированы 8 сортов сливы китайской (Prunus salicina L.): Алтайская юбилейная, Красносельская, Краснощекая, Куяшская, Пирамидальная, Пониклая, Уральская золотистая, Шершневская. Основные недостатки сложившегося сортимента - недостаточное количество крупноплодных сортов, с темно-окрашенными плодами и стабильным плодоношением, способных противостоять негативному влиянию абио- и биотических факторов окружающей среды.

Решение этих недостатков возможно за счет совершенствования сортимента сливы путем селекции и интродукции новых, адаптивных сортов, способных максимально реализовать продуктивный потенциал в условиях северного садоводства.

Цель исследования: создать новый сорт сливы китайской - адаптивный, урожайный, с высококачественными плодами для пополнения районированного сортимента Урала.

\section{Объекты и методы исследования}

Объекты исследований:

1) деревья сорта Сапфир - в селекционном саду 1995 г. посадки (ФГУП «Горно-Алтайское», Республика Алтай, с. Чемал);

2) вегетативно размноженные растения, на участке конкурсного изучения 2009 г. посадки на Челябинском государственном плодово-ягодном сортоиспытательном участке (Челябинская область, Красноармейский район).

Конкурсное испытание заложено по методике Государственного сортоиспытания [4]. В качестве контроля - районированный по Уральскому региону сорт - Уральская золотистая селекции Южно-Уральского научно-исследовательского института садоводства и картофрелеводства филиала ФГБНУ «Уральский федеральный аграрный научно-исследовательский центр Уральского отделения Российской академии наук» (г. Челябинск). Изучаемые сорта привиты на сеянцы вишни песчаной (Prunus pumila L.). Схема посадки $5 \times 3$ м. Участок на богаре. Система содержания междурядий в саду - черный пар. Агротехника общепринятая для возделывания сливы на Южном Урале.

Все исследования выполнены согласно общепринятым методикам $[9,10]$.

Экспериментальный сад ФГУП «ГорноАлтайское» заложен на западном склоне горы Изюк, на высоте около 500 м над уровнем моря. Климат среднегорья Алтая умеренно континентальный, среднегодовая температура воздуха $1,0{ }^{\circ} \mathrm{C}$ в (в последние годы $3,5-4,0{ }^{\circ} \mathrm{C}$ ), абсолютный минимум температуры в зимний период - минус $40,2^{\circ} \mathrm{C}$ в 2000-2001 гг. Среднегодовое количество осадков - 529 мм, в зимний период непостоянный снежный покров. Почвенный покров представлен горным черноземом, подстилаемый многометровыми толщами гальки и булыжника. Перегнойно-аккумулятивный горизонт - в среднем 40-60 см. Условия сада в Чемале не позволили выявить настоящую ценность нового сорта. В целом климат среднегорья Алтая является благоприятным для про- 
мышленного и любительского возделывания сливы, но повторяющиеся зимы с критическими температурами, заморозки и низкие температуры в период цветения значительно снижают продуктивность этой культуры [5].

Климат северной лесостепной зоны Челябинской области континентальный, среднегодовая температура составляет $2,0^{\circ} \mathrm{C}$. Основными особенностями климата является холодная и продолжительная зима - 160-170 дней с частыми метелями и сухое, жаркое лето с периодически повторяющимися засушливыми периодами. Абсолютный минимум температуры - минус $49{ }^{\circ} \mathrm{C}$. Среднегодовое количество осадков 424 мм. Сумма эфффективных температур составляет 1900-2000 ${ }^{\circ} \mathrm{C}$. Продолжительность безморозного периода - от 105 до 120 дней [1].

Изучение на Челябинском ГСУ выявило настоящую ценность нового сорта Сапфир.

Результаты исследования. Сорт Сапфир (Г 11-150, Черная ранняя, Чернослив ранний) выведен в ФГУП «Горно-Алтайское» в среднегорье Алтая (с. Чемал) методом отдаленной межвидовой гибридизации (Катунская × (Аштаракская 2 × Пирамидальная). Авторы: М. Н. Мaтюнин, Т. Н. Слепнева.

В качестве родительских форм использованы сорта сливы уссурийской ( $P$. salicina subsp. ussuriensis Koval. et. Kost.) - Катунская и Пирамидальная, а так же Армянская алыча (Prunus cerasifera Ehrh.) - сорт Аштаракская 2.

Сорта сливы Катунская и Пирамидальная, передают потомству высокую зимостойкость, стабильную урожайность и скороплодность. Сорт Пирамидальная районирован в суровом климате Бурятии [3], а Катунская в среднегорье Алтая выделена за высокую зимостойкость $[5,6]$.

Сорт алычи Аштаракская 2 обладает крупными, высокотехнологичными и качественными плодами, поздним сроком созревания и лежкостью плодов более месяца в процессе хранения [2].

Посев семян выполнен в 1991 г. В 2002 г. сеянец выделен в элиту. В 2009 г. сорт передан на Челябинский ГСУ для первичного сортоизучения. С 2016 г. сорт Сапфир проходит Государственное сортоиспытание.

В саду первичного изучения 2009 г. посадки однолетними саженцами сорт Сапфир и контрольный сорт Уральская золотистая вступили в плодоношение на четвертый год.
Деревья сорта Сапфир среднерослые, среднерастущие, высотой до 3,5 м. Форма кроны раскидистая, средней густоты и облиственности (рис. 1). Основной тип плодовых образований плодовые веточки. Кора ветвей коричневосерая, шелушащаяся.

Побеги средней толщины и длины, слегка изогнутые, с малочисленными мелкими выступающими чечевичками, опушение отсутствует. Цвет коры побегов красновато-коричневый, проявление покровной окраски на солнечной стороне сильное. Междоузлия короткие $-2,0$ см. Почки вегетативные - мелкие, конусовидные слегка отклоненные от побега, генеративные округлые.

Лист обратнояйцевидный, острозаостренный, длинный $(10,2$ см), средней ширины (5,5 см) (рис. 2). Летняя окраска поверхности листовой пластинки сверху зеленая, глянцевая, слегка морщинистая, снизу - светло-зеленая, осенняя окраска желто-красная. Лист направлен вниз. Кончик листа острый. Пластинка листа слегка вогнутая, вершина листа резко заостренная, с узкоклиновидным основанием. Опушение с нижней стороны листа отсутствует. Край листа дваждыгородчатый, цельный. Прилистники раноопадающие, длинные, сильнорассеченные. Черешок средней длины и толщины, зеленый (к осени проявляется пигментация), глубина бороздки мелкая, слабоопушенная. Железки мелкие, желтого цвета приподнятые, овальные, расположены на основании листа и на черешке, число железок среднее (2-3).

Плоды массой 25,5 г (max - 30,1 г), округлой формы, одномерные (рис. 3). Основная окраска плода желтая, покровная - синяя с сильным восковым налетом. Воронка мелкая, средняя. Брюшной шов выделяющийся, средней глубины. Плодоножка средней длины и толщины с хорошим прикреплением к ветви и прочным к косточке, при созревании плодов не осыпается. Мякоть желтая, нежная, средней сочности, плотная. Сок бесцветный. Косточка мелкая, овальная, почти шаровидной формы со шва, составляет $5,1 \%$ в общей массе плода. Срок созревания - вторая декада августа. Транспортабельность хорошая. Сорт универсального назначения.

Основные хозяйственно-биологические показатели сортов Уральская золотистая и Сапфир представлены в таблице. 


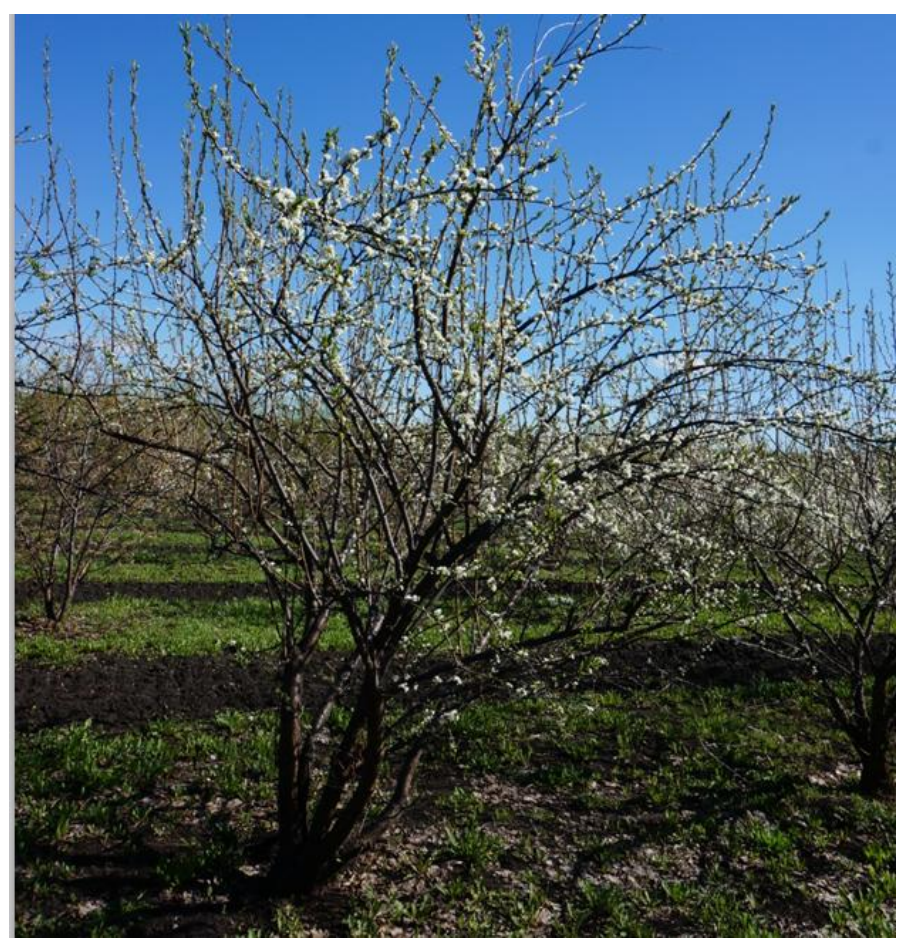

Puc. 1. Дерево сорта сливы Сапфир, возраст 8 лет (Челябинский ГСУ, 2017 г. Фото Т. Н. Слепнева)

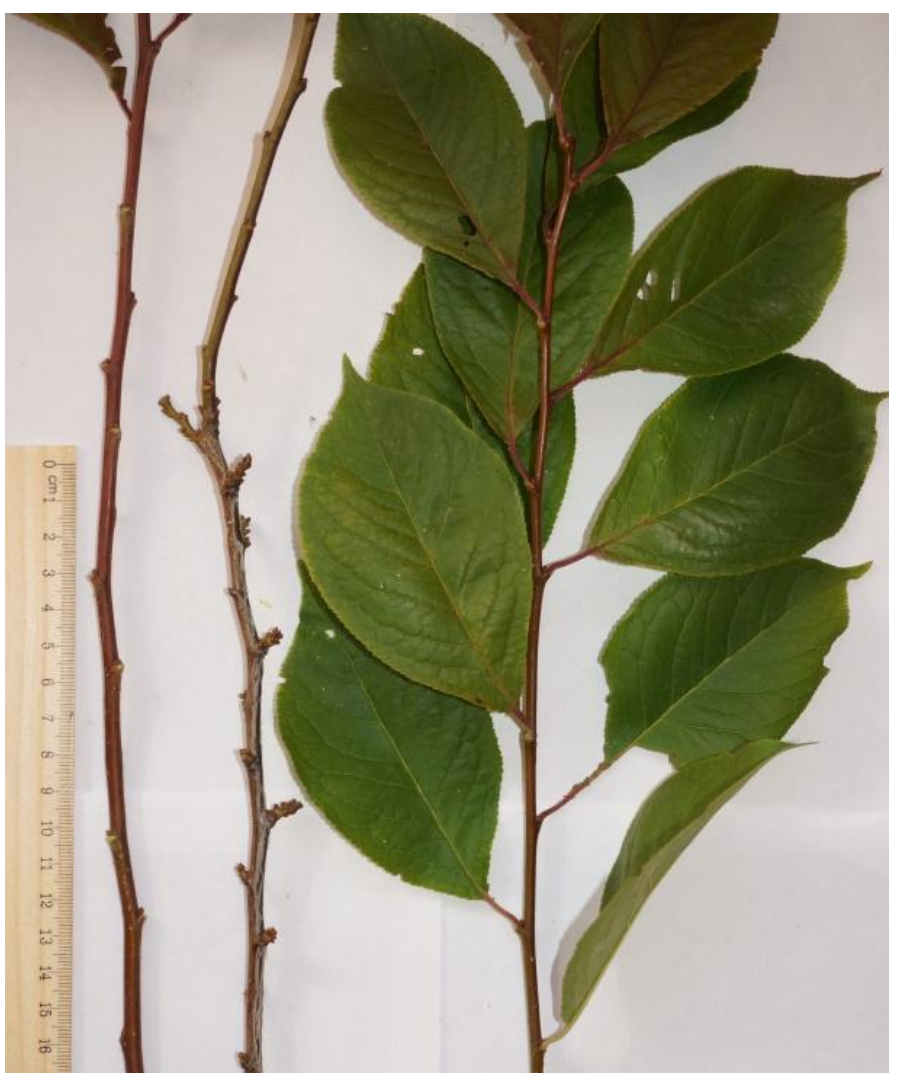

Puc. 2. Побеги и листья сорта сливы Cапфрир

(Челябинский ГСУ, 2017 г. Фото Т. Н. Слепнева) 


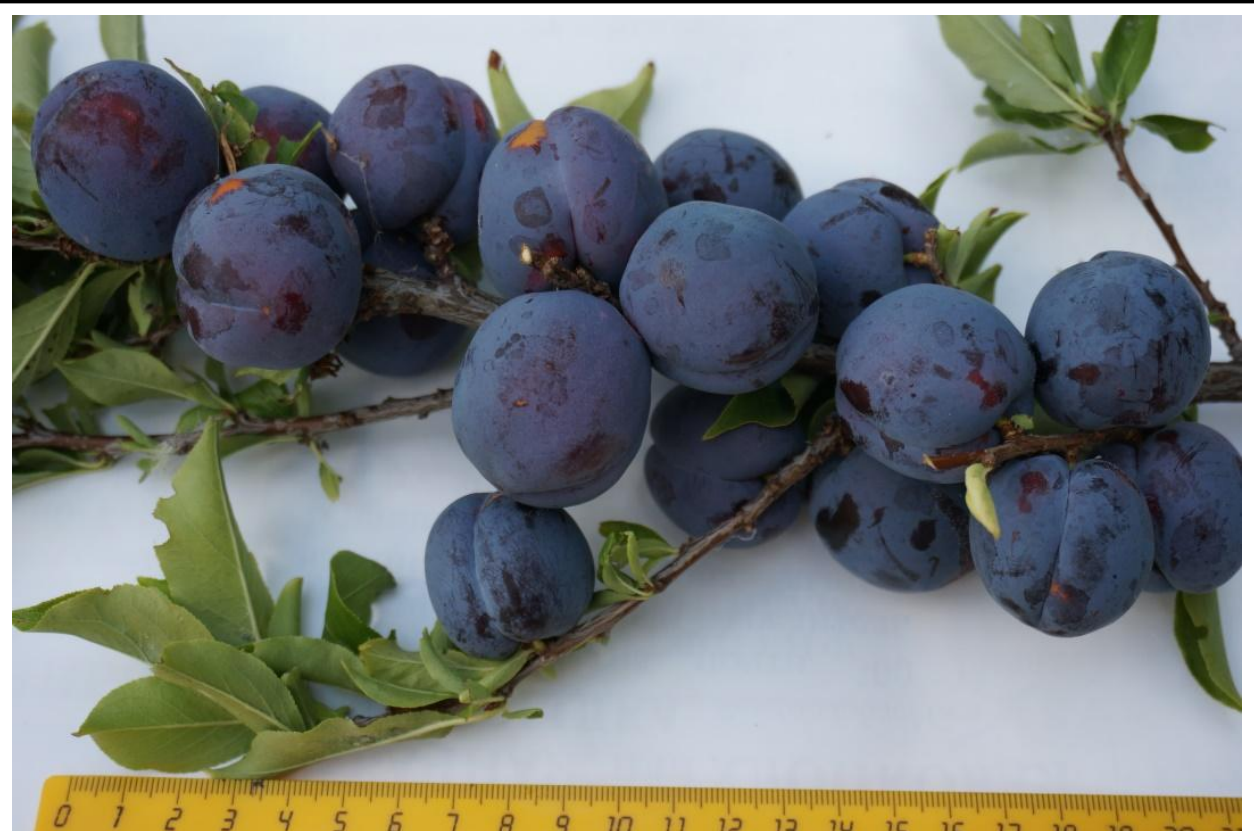

Puc. 3. Плоды сорта сливы китайской Сапфир (Челябинский ГСу, 2017 г. Фото Т.Н. Слепнева)

\section{Хозяйственно-биологическая характеристика сорта сливы китайской Сапфир, 2011-2019 гг. (Челябинский ГСУ)}

\begin{tabular}{|l|c|c|}
\hline \multicolumn{1}{|c|}{ Хозяйственно-биологический показатель } & $\begin{array}{c}\text { Уральская золотистая } \\
\text { (контроль) }\end{array}$ & Сапфир \\
\hline $\begin{array}{l}\text { Общая степень подмерзания в критическую } \\
\text { зиму 2010-2011гг., } \mathrm{t}=-39{ }^{\circ} \mathrm{C}, \text { балл }\end{array}$ & 1,0 & 0,4 \\
\hline Максимальное поражение болезнями & & \\
в 2016 г., балл: & & 0 \\
монилиоз плодов & 4,5 & 0 \\
клястероспориоз & 3,0 & 0 \\
\hline Повреждение тлей, балл & 2,0 & 5,3 \\
\hline Урожайность средняя, т/га & 3,8 & 25,5 \\
\hline Масса плода, г: & 16,7 & 30,1 \\
средняя & 23,4 & 5,1 \\
максимальная & 6,2 & Хорошая \\
\hline Содержание косточки к общей массе плода, \% & Хорошая & 4,6 \\
\hline Отделяемость косточки & 4,2 & 19,9 \\
\hline Дегустационная оценка, балл & 14,2 & 12,3 \\
\hline Химический состав плодов: & 10,1 & 0,52 \\
содержание сухих растворимых веществ, \% & 1,4 & 7,04 \\
\hline содержание сахаров, \% & 4,5 & 16.08 \\
\hline содержание кислот, \% & Хорошая при своевре- & Очень хорошая \\
содержание витамина С, мг/100 г & менном сборе & \\
\hline Транспортабельность плодов & 14.08 & \\
\hline Наступление календарного срока & & \\
съемной зрелости & & \\
\hline
\end{tabular}


В годы исследования абсолютный минимум наблюдался в зимний период 2010-2011 гг. и составил минус $39^{\circ} \mathrm{C}$. Отмечено подмерзание контрольного сорта Уральская золотистая - 1,0 балл, у сорта Сапфир - 0,4 балла. Характер подмерзания - однолетние ветви. В январе 2014 г. наблюдалось понижение температуры воздуха до минус $38{ }^{\circ} \mathrm{C}$ с последующими оттепелями, что привело к гибели цветковых почек у обоих сортов на $100 \%$.

В последние годы очень актуальным стало такое заболевание, как плодовая гниль, или монилиоз (Monilia fructigena Pers.), активному развитию которого способствует обилие осадков в период созревания плодов. За годы наблюдений на сорте Сапфир не наблюдалось поражения плодов монилиозом и клястероспориозом (Clasterosporium carpophilum Lev). У контрольного сорта Уральская золотистая максимальное поражение 4,5 балла отмечено в 2016 г. Контрольный сорт также ежегодно поражается клястероспориозом.

На Урале и в других регионах Российской Федерации слива страдает от повреждения тлей. Сорт Сапфир за годы наблюдений показал стабильную устойчивость, у контрольного сорта максимальное повреждение однолетних побегов тлей составило 2,0 балла. По результатам многолетних исследований, Сапфир проявил устойчивость к болезням и вредителям. За годы изучения средняя урожайность изучаемого сорта составила 5,3 т/га, у контрольного - 3,8 т/га.

Новый сорт качественно отличается от контрольного крупноплодностью и вкусовыми качествами плодов. Средняя масса плодов сорта Сапфир составила 25,6 г, что на 53 \% выше, чем у контрольного сорта. Дегустационная оценка плодов сорта Сапфир в свежем виде выше, чем у контрольного. и составила 4,6 балла. По качеству биохимического состава плодов Сапфир также превосходит контрольный сорт Уральская золотистая. В его плодах высокое содержание сухих растворимых веществ $(19,9 \%)$, сахаров (12,3\%), среднее содержание кислоты (0,52 \%) и витамина С (7,04 мг/100 г).

Плоды сливы сорта Сапфир хранятся в условиях холодильника в течение 1-2 месяцев. Они пригодны как для потребления в свежем виде, так и для переработки. Сорт является ценным сырьем для производства сухофруктов.

\section{Выводы}

1. Результаты многолетних исследований показали, что сорт сливы Сапфир сочетает в себе высокие адаптивные свойства к абио- и биотическим факторам Уральского региона, крупноплодность, высокие вкусовые качества, темную окраску плодов, стабильную урожайность. С 2016 г. сорт проходит в Государственное сортоиспытание.

2. Сорт можно рекомендовать для привлечения в селекцию сливы, как комплексный источник качества плодов (синяя окраска, крупноплодность, пригодность плодов для разных видов переработки, хранения) и адаптивности к суровым климатическим условиям Урала и Сибири.

\section{Литература}

1. Андреева М.А. Природа Челябинской области. 2-е изд., испр. Челябинск: Изд-во ЧГПУ, 2001. $269 \mathrm{c.}$

2. Еремин Г.В. Перспективные сорта алычи для производства и селекционного использования // Селекция и технология выращивания плодовых культур. М.: Колос, 1978. C. 14-18.

3. Киргизова Г.Т. Новый адаптивный сорт сливы для Бурятии // Научное обеспечение адаптивного садоводства Уральского региона: сб. науч. тр. / ГНУ Свердловская СС ВСТИСП Россельхозакадемии. Екатеринбург, 2010. С. 82-84.

4. Методика государственного сортоиспытания сельскохозяйственных культур. Вып. 5. М.: Колос, 1970.

5. Матюнин М.Н. Биологические особенности и селекция косточковых культур в Горном Алтае. Новосибирск, 2016. 344 с.

6. Мочалова О.В., Матюнин М.Н. Цитоэмбриология и селекция отдаленных гибридов и полиплоидов косточковых растений на Алтае / РАСХН, Сиб. отд-ние, НИИСС им. М.А. Лисавенко. Новосибирск, 2002. 232 с.

7. Нигматзянов Р.А., Сорокопудов В.Н., Куклина А.Г. Качественная характеристика сортов смородины золотистой (Ribes aureum Pursh) в России // Вестник КрасГАУ. 2020. № 3. C. 29-34. DOI:10.36718/18194036-2020-3-29-34. 
8. Нигматзянов Р.А., Сорокопудов В.Н. Перспективы селекции смородины черной по качеству ягод в условиях Башкирского Предуралья // Вестник КрасГАУ. 2020. № 1. C. 29-34. DOI:10.36718/1819-4036-2020-134-39.

9. Программа и методика сортоизучения плодовых, ягодных и орехоплодных культур / под ред. Е.Н Седова, Т.П. Огольщовой. Орел: Изд-во ВНИИСПК, 1999. 606 с.

10. Программа и методика селекции плодовых, ягодных и орехоплодных культур. Орел, 1995. $502 \mathrm{c}$.

11. Ренгартен Г.А., Сорокопудов В.Н. Оценка сортообразцов черемухи в зависимости от их генетического происхождения на северовостоке России // Вестник КрасГАУ. 2019. № 3 (144). C. 51-57.

12. Слепнева Т.Н., Чеботок Е.М., Макаренко С.А. Основные результаты научной деятельности Свердловской селекционной станции садоводства за 2017 год // Современное садоводство - Contemporary horticulture. 2018. № 3. C. 103-113. DOI: 10.24411/2312-6701-2018-10321.

\section{Literatura}

1. Andreeva M.A. Priroda Cheljabinskoj oblasti. 2-e izd., ispr. Cheljabinsk: Izd-vo ChGPU, 2001. $269 \mathrm{~s}$.

2. Eremin G.V. Perspektivnye sorta alychi dlja proizvodstva i selekcionnogo ispol'zovanija /I Selekcija i tehnologija vyrashhivanija plodovyh kul'tur. M.: Kolos, 1978. S. 14-18.

3. Kirgizova G.T. Novyj adaptivnyj sort slivy dlja Burjatii // Nauchnoe obespechenie adaptivenogo sadovodstva Ural'skogo regiona: sb. nauch. tr. / GNU Sverdlovskaja SS VSTISP Rossel'hozakademii. Ekaterinburg, 2010. S. 82-84.
4. Metodika gosudarstvennogo sortoispytanija sel'skohozjajstvennyh kul'tur. Vyp. 5. M.: Kolos, 1970.

5. Matjunin M.N. Biologicheskie osobennosti i selekcija kostochkovyh kul'tur v Gornom Altae. Novosibirsk, 2016. $344 \mathrm{~s}$.

6. Mochalova O.V., Matjunin M.N. Citojembriologija i selekcija otdalennyh gibridov i poliploidov kostochkovyh rastenij na Altae / RASHN, Sib. otd-nie, NIISS im. M.A. Lisavenko. Novosibirsk, 2002. $232 \mathrm{~s}$.

7. Nigmatzjanov R.A., Sorokopudov V.N., Kuklina A.G. Kachestvennaja harakteristika sortov smorodiny zolotistoj (Ribes aureum Pursh) v Rossii // Vestnik KrasGAU. 2020. № 3. S. 2934. DOI:10.36718/1819-4036-2020-3-29-34.

8. Nigmatzjanov R.A., Sorokopudov V.N. Perspektivy selekcii smorodiny chernoj po kachestvu jagod $v$ uslovijah Bashkirskogo Predural'ja // Vestnik KrasGAU. 2020. № 1. S. 29-34. DOI:10.36718/1819-4036-2020-1-3439.

9. Programma i metodika sortoizuchenija plodovyh, jagodnyh i orehoplodnyh kul'tur / pod red. E.N Sedova, T.P. Ogol'covoj. Orel: Izd-vo VNIISPK, 1999. $606 \mathrm{~s}$.

10. Programma i metodika selekcii plodovyh, jagodnyh i orehoplodnyh kul'tur. Orel, 1995. $502 \mathrm{~s}$.

11. Rengarten G.A., Sorokopudov V.N. Ocenka sortoobrazcov cheremuhi v zavisimosti ot in geneticheskogo proishozhdenija na severovostoke Rossii // Vestnik KrasGAU. 2019. № 3 (144). S. 51-57.

12. Slepneva T.N., Chebotok E.M., Makarenko S.A. Osnovnye rezul'taty nauchnoj dejatel'nosti Sverdlovskoj selekcionnoj stancii sadovodstva za 2017 god // Sovremennoe sadovodstvo - Contemporary horticulture. 2018. № 3. S. 103-113. DOI: 10.24411/23126701-2018-10321. 